\title{
A Descriptive Analysis of Barriers Faced by Females in Acquiring Higher Education; A Study of District Zhob, Baluchistan in Pakistan
}

\author{
Zahid Hussain Shah \\ Department of Sociology, \\ Bahauddin Zakariya University Multan, Pakistan \\ Hina Aslam \\ (CA) \\ M. Phil. Scholar \\ Department of Sociology, \\ Bahauddin Zakariya University Multan, Pakistan \\ Aisha Khan \\ Assistant Professor \\ Department of Sociology, \\ The Women University University Multan, Pakistan
}

\begin{abstract}
The current research was centered on the scholarly issues and social barriers faced by female students to get affirmation in higher education. The study expected to discover the difficulties, which the respondents needed to face to conquer the social impediments in getting advanced education. The review concentrated on huge number of social obstructions and difficulties, budgetary issues and scholastic issues that female needed to confront. Quantitative research approach was utilized to uncover the experience of respondents which they encountered while getting affirmation in college. The research was being conducted in District Zhob, Baluchistan Province, since it was encompassed by for the most part country Areas. Population of the present review comprised of the female understudies contemplating in different instructive organizations. The discoveries demonstrate that different variables in charge of social prohibition of young ladies from education area in Pakistan incorporate preservationist state of mind of family and inclination to kid's training. Notwithstanding this, female understudies likewise tended to face impression of their families about coeducation as social and religious variables to advanced education in Pakistan. The focus acknowledged with this class was "saw fears and dangers to family respect". As the individuals from conservative society, families had for the most part negative demeanor for females towards advanced education.
\end{abstract}

Keywords: Sociological Analysis, Female, Higher Education, Cultural barriers, Religious Factors. 


\section{INTRODUCTION}

Education in its overall sense is a kind of learning where data, capacities, and penchants for a get-together of people are traded beginning with one age then onto the following through teaching, planning, ask about, or simply through auto educating. Overall, it occurs through any experience that developmentally influences the way one considers, feels, or acts. Training has become a widespread common liberty all around the world. Education is major right of each resident.

With the progression of time the enhancement of society; training has taken many shapes, for example, child instruction, grown-up instruction, specialized instruction, welfare instruction, substantial training et cetera. Working out, in an extraordinarily wide logic can be summarized at a fundamental altitude as implying an undertaking or proceed that developmentally influences the psyche, disposition or substantial limit of a person. As in it is formative suggests that preparation is serving to outline something and particularly something that will dependably affect the individuals cerebrum and assets. The most away from of this is the capability to grasp and utilize tongue and science an inclination which is then used in all through a person's life. HDR (2013).

Calhoun and Light in their book "Sociology", state that commencing the moment a child is conceived, it is delegated either a female or a child on the ground of bodily facade. They affirm "Society sets up an arrangement of social desires for every sexual orientation; youngsters are instructed to comply with what their general public expects of them as either a kid or a young lady." Low-income family can't bear the charge of sufficient money to educate their children, so they choose their youngster for advanced schooling. Mindfulness regarding the importance of female instruction is not a further marvel. Be that as it may, there is hole exhibit amongst male and female youngster in education. Thus, feminine schooling rates are minor when compared with gentleman (Ghafoor, 1994).

Each person has the freedom to education, that has been alleged ever since the Universal Declaration of Human Rights (UDHR) in 1948. "Everybody has the privilege of education. Education should be free in any event in the basic and basic stages. Specialized and proficient education might be made for the most part accessible and advanced education should be similarly available to all on the premise of legitimacy." 
Education is the establishment of the system of any country. It is the best mechanism of progress. The objective of destitution decrease can be practiced by watching out for the primary drivers of scarcity, for instance, nonattendance of training and aptitudes or debilitated prosperity which will clear existing uneven characters of possibilities. Course of action of informational workplaces to all of its heaps is the responsibility of society in social perspective of the overall population. Regardless of the way that Pakistan is a signatory of the UN Education for All Framework for Action (2000) Document, that focus on female's preparation, predominantly the finish of sexual direction irregularities in basic, discretionary and progressed instruction, yet the goal of attaining Education for All in Pakistan is as yet far from classy.

To begin with the meaning of the term-Higher Education actually, present is no basic sense of advanced schooling. The widespread connotation of tertiary (post school) instruction segregates it into two sections. Sort A (Higher E.ducation) and Type B (Further Educa.tion). An advanced or higher education competence at degree level takes at least three years to end, all the additional normally four. It will have a imaginary supporting, it will be at a point which would meet the requirements somebody to effort in an specialist field and it will for the most part be educated in a domain which likewise incorporates propelled inquire about movement. Without further ado, Higher training basically and mostly tend to be college level instruction. It offers different capacities going from Higher National Diplomas and Foundation Degrees to Honors Degrees and as further step, Postgraduate tasks, for instance, Masters Degrees and Doctorates. These are seen all through the world as addressing ace fitness maintained by a broad assortment of capacities that organizations find incredibly accommodating. Advance preparing is overall joins those post graduate audits in where you can get your Master and Doctorate degrees.

Education has been of focal or fundamental importance to the advancement as well as enlargement of individual society. It can be the start, of human being knowledge, facts and mindfulness, similarly a comprehensive procedure for enhancement and modify. Education is predominantly connected to the women's ability to outline social associations on the reason of consistency by others and to achieve the basic social incredible of feeling of pride. It is imperative, as well, to flexibility (through admittance to livelihoods and the political strategy), to prosperity and life (over the relationship with genuine dependability). Training can allow women to look into administrative problems so they can promise that their voices 
and misgivings are seen and slanted to in everyone methodology. It is moreover earnest for women's passageway to the authentic system. Training is an essential commitment to human resource headway and is fundamental for the country's money related turn of events. It manufactures the gainfulness and efficiency of individuals and it yields skilled work drive that is prepared for driving the economy towards the method of attainable turn of events and achievement. The development and success of a country generally depends on upon the choices of training made open to its kinfolk. It tends to be a champion among the most able means of progress. It can assist a country with achieving its cross country destinations by methods for making minds ingrain with data, capacities and abilities to shape its future destiny. The in all cases affirmation of this reality has made care on the prerequisite to focus upon capability and simple learning modified, as an issue of cultural value as well as fairly more to develop money related turn of events, cultural thriving and social consistent quality.

Female education is so indistinguishably associated with exchange highlights of human improvement that to make it a need is to moreover turn out enhancement for an extent of various fronts, from the prosperity and position of women to beginning youth mind, since food, water and disinfection to amass fortifying, from the diminishment of child work and various sorts of maltreatment to the quiet assurance of conflicts. Guidance must give the odds to smugness; it can, most ideal situation give a rich and testing condition for the individual to examine, in his (or her) own specific way. It's a given that advance and achievement of a country generally depends on upon the choices instruction made open to its kinfolk. Instruction is the establishment of the structure of any country. It is the most serious instrument of progress. The target of desperation diminishing can be cultivated by watching out for the primary drivers of poverty, for instance, nonappearance of training and capacities or debilitated prosperity which will clear existing uneven characters of possibilities. Plan of informational workplaces to all of its masses is the dedication of society in social perspective of the overall population. In spite of the way that Pakistan is a signatory of the UN Education for All Framework for Action (2000) Document, which puts extensive prominence on women's' training, predominantly the finish of sexual direction irregularities in basic, assistant and progressed instruction, yet the goal of attaining Education for All in Pakistan is as yet far from attractive. The condition of instruction, particularly womanly training, is as yet horrifying. The female training rate evidently exhibits that enthusiasm for individual improvement slants on the way to preferring males over females. Females explicitly have 
restricted chances to get progressed training and achieve capable and specific degrees. Pakistan has for a long while been a worldwide oddity in sex holes in instruction. Youngsters wait behind youngsters in instruction access, in the idea of coaching open, and in the consequences of training.

Generally the literacy rate of Pakistan is fifty seven percent (sixty nine percent for men and forty five percent for women). Literacy tends to be higher in urban areas (seventy four percent) than in rural areas (forty eight percent). Literacy rate for males is (sixty nine percent) and for females is (forty five percent) (PSLM), 2011-2012). Young ladies are likewise denied from their primary educational right. Approximately seventy six percent of female adult population is illiterate. Then again seventy five percent female understudies left at the essential level. The gender difference is outrageous from the way that fifty seven percent grade school age young ladies go to class when contrasted with $89 \%$ young men.

Gender inequality in instruction is surprising. Youngsters are more loath to get the opportunity to class, to remain in school or to achieve in training. Training enables men and women to state their privileges and comprehend their potential in the monetary, political and social fields. It is in like manner irrefutably the best way to deal with lift people out of desperation. Instructions accept a particularly fundamental part as a foundation for youngsters' improvement towards grown-up life. It should be a trademark some portion of any system to address the sex based persecution women and youngsters that residual parts overwhelming in various social requests.

\section{Objectives of the Study}

1. To study the academic problems faced by female student in Baluchistan.

2. To explore the hurdles and barriers those females face in acquiring higher education.

Hypothesis; "There is a relationship between rigid cultural beliefs and higher education of the female students in Baluchistan".

Fauzia Maqsood (2012) reasoned that label gender roles were the intuition of estimations of a male predominant society. The review concerted on the large number of social obstructions and issues female needed to face, adapting methodologies received by young ladies to 
devastate these hindrances and outcomes young ladies needed to experience amid adapting techniques and the effect of their battle to obtain advanced education on alternate young ladies of their family and group.

Noreen (2011) led an examination that Education has been of focal centrality to the enhancement of human culture. The global group's dedication to all inclusive training was first set down in the 1984 Universal Declaration of Human rights. In Pakistan, mainly in provincial and sub-urban zones, ladies are set generally at the base end of the instructive framework in distinction with their male partners. In this circumstance, instruction can assume a key part in uplifting the status of ladies.

Aslam (2009) inferred that differential work advertise comes back to male and female instruction are the clarification of vast sexual orientation hole of training in Pakistan. Private comes back to instruction of guys and females happen. The information from Integrated Household Survey (2002) was utilized. Ladies are more disposed towards instruction and for the most part ladies education is higher than instruction of men.

Rasian (2009) assumed that there are various preventions and troubles that must be defied by the making countries concerning advanced education. There is reliably and nonappearance of institutional arrangement and cash related restrictions. Making countries need to stand up to various restrictions with respect to advanced education since they can't face the challenges of whimsical overall economy due to spending objectives. The researcher wrapped up crafted by [ Schwartzman(2001), (2004)],to separated the challenges and impediments regarding advanced education in making countries. Schwartzman (2001) contemplated that notwithstanding far reaching contrasts in cultural structures, social and chronicled establishments, advanced education need to face real challenges .Higher instruction requires incredible fiscal conditions yet amazingly helpless countries need to go up against A significant proportion of budgetary difficulty regarding advanced education commission.

Addy (2008) induced that deterrents to youngsters guidance join diverse free market movement side segments, for instance, unbendable social models, opportunity costs sections cut down pace of benefits for youngsters, female headed nuclear families, nonappearance of inspirations for youngsters preparing, non-fulfillment of bureaucratic assurances about sexual direction value in guidance portion, prosperity mindfulness toward young women and nonattendance of female instructors. Chitrakar (2007) examined that the obstacle of sexual 
direction partition reliably exist especially in different land zones like India, Pakistan, Nepal, Afghanistan besides in different socio-phonetic get-togethers.

Chitrakar (2007) deduced that the limit of sexual orientation separation constantly exist especially in different land districts like India, Pakistan, Nepal, Afghanistan moreover in different socio-etymological get-togethers. sex segregation exists especially in the selection of youngsters when significant divergence can be viewed. Various variations moreover outline the base of sexual orientation separation which consolidates nation urban setting, phonetic get-togethers, social shows and sex job speculations. Training encourages the youngsters to make them socially and socially empowered. Regardless, heartbreakingly youngsters are incapacitated from looking for after instruction that prompts to improved paying business in their future. Various obstacles for the instruction of youngsters are impediments to get to, limits to consistency, quality limits, family checks, poverty, and moderate aura of family and issues of security for young women. Yet differing game plans has been made to invalidate sexual orientation segregation yet generally they are quantitative rather than emotional and they watched out for the issues like family benefit, issues of prosperity, authentic frameworks, select necessities with youngsters, level of chance use structure for young women and firm characteristics associated with young women instruction. Provincial urban setting, phonetic get-togethers, social traditions and sex part speculations are moreover considered accountable for low pace of females training. Abu-Ghaida (2004) led an examination about the Millennium Summit, the world group vowed to advance sexual orientation equity and pick it as an unequivocal focus about accomplishment of sex value in essential and supplementary schooling in all state of the world. The scientist appraises what the fixed cost as far as development, sworn off ripeness, mortality and under nourishment decrease will be for forty five nations that are on existing projections.

Council member (1998) (1998) completed that sex hole in mentoring is frustrating given that the typical returns to an individual for extended coaching as estimated by comparing pay contrast by sexual direction. The pro researches possible explanations for the disparity using a model of parental enthusiasm for youths preparing.

Hill (1995) contemplated that confirmation transversely over regions on the planet reveals structures in school enrollment extents and instruction that are disconnected along sexual orientation lines. In the making scene, beside most countries in Latin America and Caribbean, 
selection extents of youngsters fall behind young fellows at all degrees of instruction. Generally speaking capability rates for grown-up men far beat than women. Whereas educational progress has been appreciated by both genders, these advances have ignored to take out the gender gaps. Education enhances work advertise profitability and wage development for all, yet taught ladies effectsly affect social prosperity not generally measured by market. A Rising level of education intensifies ladies proficiency in the residence which thusly can inflate family comfort, youngster endurance and interest in human assets. The social advantages from ladies education run from improvement financial development to amplifying the normal life desire in the populace. These advantages will enhance the significance of political procedures. This paper surveys late trial inquire about that investigates the advantages of females' education, clarify the significance of ladies education for nation level, measures of financial advancement and take a gander at the ramifications of gender gaps in education for expanding social affluence.

\section{Research methods of the study}

The universe of the present research was District Zhob, Baluchistan in Pakistan. The research is quantitative in nature. The researcher used the multistage sampling technique for data collection. The total sample of the present study consisted of 90 respondents. $n$ the wake of drawing the example and planning the suitable exploration method, information was gathered through questionnaire as an apparatus for information assortment measure. Questionnaire was planned based on data drawn from the survey of writing and information on the markers. Semi-Structured inquiries were utilized by the analyst with the end goal of development of questionnaire. The inquiries are about the essential segment data of family. The researcher collected the detailed information from the respondents.

Chi- square was applied to find out the relationship between certain independent and dependent variables. 
Demographic profile of respondents

\begin{tabular}{cccc}
\hline Category & Frequency & Percentage \\
\hline Age & 10 to 15 years & 40 & 20.0 \\
& 15 to 20 years & 50 & 25.0 \\
20 to 25 years & 50 & 25.0 \\
Above 25 years & 53 & 26.5
\end{tabular}

Family Structure

$\begin{array}{lccc} & \text { Joint } & 73 & 36.5 \\ & \text { Nuclear } & 77 & 38.5 \\ \text { Extended } & 49 & 24.5 \\ \text { Residential Area } & & & \\ & \text { Rural } & 90 & 44.5 \\ \text { Education } & \text { Urban } & 110 & 56.0 \\ & & & \\ & \text { Intermediate } & 75 & 37.5 \\ & \text { Bachelor } & 75 & 37.5\end{array}$

Family income

$\begin{array}{ccc}\text { Rs. } 5000 /- \text { to Rs. } 10000 /- & 22 & 11.0 \\ \text { Rs. } 10000 /- \text { to Rs. } 15000 /- & 65 & 32.5 \\ \text { Rs. } 15000 /- \text { to Rs. } 20000 /- & 73 & 36.5 \\ \text { Rs. } 20000 /- \text { to Rs. } 25000 /- & 39 & 19.5 \\ \text { Rs. } 10000 /- \text { to Rs. } 15000 /- & 65 & 32.5 \\ \text { any other } & 19 & 9.5\end{array}$

Accommodation

$\begin{array}{ccc}\text { Own } & 61 & 30.5 \\ \text { Rented } & 44 & 22.0 \\ \text { official residence } & 31 & 15.5 \\ \text { living with other } & 41 & 19.0 \\ \text { any other } & 19 & 9.5\end{array}$

\section{Hypothesis testing}

Null Hypothesis; "There is no association between rigid cultural beliefs and higher education". 
Alternate Hypothesis; "There is an association between rigid cultural beliefs and higher education".

The above table shows that there is a significant relationship between the dependent (Higher Education) and independent (Cultural Beliefs) variables.

\section{Correlation matrix between selected variables}

**Correlation is significant at the 0.01 level.

\section{Conclusion}

The research was conducted in District Zhob, Baluchistan in Pakistan, the area was mostly covered by rural setup. Populace of the current investigation comprised of the female understudies concentrating in instructive organizations. The classification of money related imperatives incorporated the subject of the shortage of assets apportioned to young ladies. Specialist investigated that on account of poor monetary conditions guardians favored their child's training when contrasted with girl's instruction. "Because of the restricted assets guardians settle on decision between little girl's training and child's instruction". Female

\begin{tabular}{lcccc}
\hline \multicolumn{1}{c}{ Variables } & Mean & St. Deviation & R & $\boldsymbol{P}$ \\
\hline Cultural beliefs & 2.11 & 1.203 & $.262^{* *}$ & 0.001 \\
Higher education & 1.78 & 0.923 & & \\
\hline
\end{tabular}

understudies additionally confronted impression of their families about co-instruction as a social obstruction to advanced education. The topic identified with this classification was "saw fears and dangers to family respect".

\section{Suggestions}

1. Portion of funds should be made easy from province to districts \& then to higher educational institutions.

2. Conservative demeanor of family and network may b improved through media mindfulness.

3. Such educational policies at provincial level will be obliging in the enhancement of womanly education in the locale. 
4. To reinforce feminine education in the area, there must be some scholarships so that they may continue their studies without any difficulty.

5. Enhancement in teachers training will clear the way to female education in the area.

6. Awareness drive among the females should be initiated regarding their basic right of education 


\section{References:}

1. Abu-Ghaida, D. and S. Klasen. 2004. "The Costs of Missing the Millennium Development Goals on Gender Equity." World Development, Vol.32, No.7, pp.1075-1107.

2. Addy, E.S. 2008. "Gender Equality in Juniors and Senior Secondary Education in Sub-Saharan Africa." The International Bank for Reconstruction and Development. The World Bank.

3. Alderman, H. and E.M. King. 1998. "Gender Differences in Parental Investment in Education." Structural Change and Economic Dynamics, Vol.9, No.4, pp.453-468.

4. Aslam, M. 2009. "Education Gender Gaps in Pakistan: Is the Labor Market to Blame?" Economic Development and Cultural Change, Vol.57, pp.747-784.

5. Aslam, M. 2009. "The Relative Effectiveness of Government and Private Schools in Pakistan: Are Girls Worse Off?” Education Economics, Vol.17, No.3, pp.329-354.

6. Chitrakar, R. (2009). Overcoming barriers to girls' education in South Asia: Deepening the analysis. Published by UNICEF ROSA.

7. Heise, L. , M. Ellsberg and M. Gottemoeller. 1999. "Ending Violence Against Women: Population Reports. Vol.27, No.4. Population Information Programmes, Center for Communication Programmes, The John Hopkins University.

8. Hill, M.A. and E. M. King. 1995. “Women's Education and Economic Well Being." Feminist Economics, Vol.1, No.2, pp.21-46.

9. Hill, M.A. and E. M. King. 1995. "Women's Education and Economic Well Being." Feminist Economics, Vol.1, No.2, pp.21-46.

10. Jehan, R. 1996. "The Exclusive Agenda: Mainstreaming Women in Development." The Pakistan Development Review, Vol.35, No.4, pp.825-834.

11. Klasen, S. 2002. "Low Schooling for Girls, Slower Growth for All? Cross Country evidence on the Effect of Gender Inequality in Education on Economic Development." The World Bank Economic Review, Vol.16, No.3, pp.245-373.

12. Lewis, M. A. and M. E. Lockheed, Eds. (2007). Gender, Education, and Exclusion: Case Studies from the Developing World, Gender, Education, and Exclusion.

13. Lloyed, C.B. , C. Mete, and M.J. Grant. 2009. "The Implications of Changing Educational and Family Circumstances for Children's Grade Progression in Rural Pakistan: 1997-2004." Economics of Education Review, Vol.28, No. 4, pp.152-160.

14. Maqsood, F. (2014). Impact of Globalization on Female Labor Force Participation in the SAARC Region. Pakistan Journal of Social Sciences (PJSS), 34(2), 523-533.

15. Noureen, G. (2011). Women's Education in Pakistan: Hidden Fences on Open Frontiers. Asian Social Science, 7(2), 79.

16. Yangt.2013. "Girls Education in the $21^{\text {st }}$ century." The International Bank for the Reconstruction and Development. The World Bank, Washington DC. 